\title{
The use of DNA barcoding to avoid adulteration in olive plant leaf products
}

\author{
RAYAN PARTOVI ${ }^{1}$, ALIREZA IRANBAKHSH ${ }^{1, \boldsymbol{v}}$, MASOUD SHEIDAI ${ }^{2}$, MOSTAFA EBADI ${ }^{3}$ \\ ${ }^{1}$ Department of Biology, Science and Research Branch, Islamic Azad University. Tehran, Iran \\ "email: iranbakhsh@iau.ac.ir \\ ${ }^{2}$ Faculty of Life Sciences \& Biotechnology, Shahid Beheshti University. Tehran, Iran \\ ${ }^{3}$ Department of Biology, Islamic Azad University, Damghan Branch. Damghan, Semnan Province, Iran \\ Manuscript received: 10 January 2021. Revision accepted: 17 March 2021.
}

\begin{abstract}
Partovi R, Iranbakhsh A, Sheidai M, Ebadi M. 2020. The use of DNA barcoding to avoid adulteration in olive plant leaf products. Asian J For 5: 42-47. The leaves of olive plant species, either the cultivated (Olea europaea) and the wild (O. europaea var. Cuspidata) have been used for medicinal uses in Iran. The first species leaves have been used to control the blood pressure, while the leaves of wild olive have been used for abortion by locals. Our preliminary inspection of the medicinal plant market revealed that the leaves of these two olive species were sold mistakenly to the consumers and their health might be at risk. Therefore, we performed this investigation to produce DNA barcodes for correct identification of these two olive species and also identify the potential adulteration in our local market. We used Internal transcribed spacer (ITS) as well as plastid genome trnL-F intergenic spacer and ribosomal protein L16 (rpL16) sequences. These sequences after alignment and curation produced DNA barcodes that can differentiate the two olive species from each other. The phylogenetic trees constructed also separated the samples of these olive species and confirmed the potential use of these short DNA sequences for olive barcoding. The present study revealed that some of the local shops mistakenly sell the wild olive leaves instead of the cultivated olive leaf to be used for blood pressure. This mistake endangers the health of pregnant women consumers if they carry a child. We suggest using a combination of nuclear ITS and plastid intergenic spacer (trnL-F and rpL16) regions for DNA barcoding of olive plants to avoid leaf product adulteration.
\end{abstract}

Keyword: DNA barcoding, medicinal market, olive, rpL16,trnL-F

\section{INTRODUCTION}

The olive plant (Olea europaea L.) complex occurs in the Canary Islands, the Mediterranean region, south-west Asia, Sino-Himalayan region, eastern as well as southern Africa (Green 2002). While African olive is a tropical wild olive, which is geographically isolated from its Mediterranean relatives (Zohary 1995). In the recent revision of Olea (Green 2002), the name Olea europaea subsp. cuspidata is proposed for the wild olive occurring in South to North-East Africa and southwest Asia.

In Iran, the olive plant occurs in both cultivated (Olea europaea subsp. europaea), and wild (Olea europaea subsp. cuspidata (Wall. \& G. Don) Cif.). The wild Olea europaea subsp. cuspidata is naturally distributed in southern parts of Iran. Both cultivated and wild olive plants have edible and/or medicinal values. The cultivated olive (O. europaea subsp. europaea) is mainly used for olive oil, but also its leaves have been used to reduce blood pressure (Lockyer et al. 2017). Similarly, the wild olive ( $O$. cuspidata) has medicinal properties like antibacterial, antifungal and antioxidant activity (Masoko and Makgapeetja 2015). The plant leaves are usually used as a remedy for eye infections, sore throat, urinary tract infections, kidney problems and backaches or headaches (Masoko and Makgapeetja 2015). The leaves are also recommended as hypotensive, emollient, febrifuge and styptic (Somova et al. 2003), and utilized for the treatment of malaria in 1854 (Altinyay et al. 2011). The leaves of both cultivated olive $O$. europaea, as well as wild olive Olea cuspidata are important medicinal plant product in Iran that is used for several disorders. The leaves of $O$. europaea are used to reduce blood pressure, while leaves of O. cuspidata are used in the form of tea to avoid pregnancy among our local people (Abaza et al. 2015; Hashmi et al. 2015).

Our preliminary inspection of these plant products in local medicinal plant market noticed that both plant species products were sold with the same name, i.e. olive, and were given for blood pressure control. This urges for attention since it might cause unintended effects, particularly regarding the adulteration of medicinal plants. Adulteration of medicinal plant products is a dangerous act that can endanger the consumer's health. This might happen due to substitution or addition of another substance in the genuine medicinal product (El Beyrouthy and Abi-Rizk 2013), or due to careless plant collection, mislabelling or presence of high level of morphological similarity of the plant species in the field (El Beyrouthy and Abi-Rizk 2013). Irrespective of the reason for adulteration, this phenomenon seems to occur frequently in medicinal plant market of developing countries (Srirama et al. 2017). Medicinal plant product adulteration can result in various and extensive harm to the people using them. For example, cases of kidney failure were reported (Srirama et al. 2017), as a result of adulteration of the roots in Stephania tetrandra with that of 
Aristolochia fangchi. Similarly, hepatotoxicity occurred due to mixing of the Cinnamomum verum bark with $C$. cassia and C. malabatrum (Srirama et al. 2017).

It is suggested to utilize integrative methods for authentication of the medicinal plants and investigating the cases for adulteration. A combination of various approaches and disciplines have been considered for such investigations such as physical and chemical methods like thin-layer chromatography (TLC) and high-performance liquid chromatography (HPLC), external morphological features, DNA sequence similarity, and phylogenetic analyses using both tree-based criteria or character-based methods (Pasqualone et al. 2016; Ghorbani et al. 2017; Yu et al. 2018). Recently, determination of the genetic distance among the studied samples and with the correct plant specimens as well as BLAST approach and DNA barcoding have also been used (Sheidai et al. 2019). A DNA barcode is unique short DNA sequences that different plant species, cultivars or races from each other and the closely related plant taxa (Sheidai et al. 2019). It enables the researchers to correctly identify the target species. This approach has been utilized to identify the medicinal plants and distinguish the original products from adulterated species/DNA (Heubl 2010; Sheidai et al. 2019).

The present study was conducted with the following aims: (i) to use different DNA regions to differentiate wild versus cultivated olive plants; (ii) to provide proper barcodes for either species, (iii) to check the potential adulteration/ or misidentification of these plant products by the local medicinal plant markets based on different barcoding approaches. For these, we first used ITS (Internal Transcribed Spacer DNA), and the chloroplast intron sequences of rpL16 and $\operatorname{trnL}-F$, for distinguishing the two plant species of O. europaea, and O. cuspidata. We finally used rpl16 sequences to identify the local market plants and investigate the potential adulteration or mistakes in these products.

\section{MATERIAL AND METHODS}

\section{Plant materials}

The wild olive (Olea cuspidata) leaf samples (four different trees) were collected in Southern Iran, where the local people collect the same plant leaves for consumption (Table 1). For ITS, six wild specimens were compared with four cultivated specimens (Table 2). For trnL-F, six wild specimens and five cultivated specimens gathered from NCBI were compared with each other (Table 3). The accession numbers of Olea species have been provided. For rp16, we also applied two out-groups, six cultivated specimens collected from different shops in Tehran, Iran, and one wild specimen (Table 4).

\section{DNA extraction and PCR reactions}

Fresh leaves were put to dry in silica gel powder. We used CTAB activated charcoal protocol (Krizman et al. 2006). The extracted DNA was examined in terms of quality and quantity by running on $0.8 \%$ agarose (Sheidai et al. 2013).

\section{ITS sequences investigation}

The complete ITS region was amplified using forward ITS5 (5'- GGA AGT AAA AGTCGTAAC AAG G- 3') and reverse primers ITS4 (5'- TCC GCT TAT TGA TAT GC3') (White et al. 1990). The following program was used for amplification of nuclear region in a PCR reaction: 5 min initial denaturation step $94^{\circ} \mathrm{C}$, followed by 40 cycles of $1 \mathrm{~min}$ at $94^{\circ} \mathrm{C} ; 1 \mathrm{~min}$ at $53.5^{\circ} \mathrm{C}$ and $2 \mathrm{~min}$ at $72^{\circ} \mathrm{C}$. The reaction was completed by a final extension step of $7 \mathrm{~min}$ at $72^{\circ} \mathrm{C}$

\section{Cp- DNA study}

The intergenic spacer of chloroplast genome rpL16 was amplified and sequenced with universal primers following the methodology of (Shaw et al. 2005; Timme et al. 2007). Each $20 \mu \mathrm{l}$ of PCR tube contained $10 \mu \mathrm{l}$ of $2 \mathrm{x}$ PCR buffer, $0.5 \mathrm{mM}$ of each primer, $200 \mathrm{mM}$ of each dNTP, 1 unit of Taq DNA polymerase (Bioron, Germany), and $1 \mu$ of template genomic DNA at $20 \mathrm{ng} \mu \mathrm{l}-1$.

The following program was used for amplification of nuclear region in a PCR reaction: 5 min initial denaturation step $94^{\circ} \mathrm{C}$, followed by 35 cycles of $1 \mathrm{~min}$ at $94^{\circ} \mathrm{C} ; 1 \mathrm{~min}$ at $54^{\circ} \mathrm{C}$ and $1 \mathrm{~min}$ at $72^{\circ} \mathrm{C}$. The reaction was completed by a final extension step of $6 \mathrm{~min}$ at $72^{\circ} \mathrm{C}$.

\section{Data analysis}

DNA regions investigated were first aligned by MUSCLE program as implemented in MEGA 7 Program (Tamura et al. 2012). They were then cured and investigated for the nucleotide difference and also to find out those nucleotides which were unique for either wild or cultivated olive plants.

Different phylogenetic trees were constructed by using PAUP ver. 4. Followed by 1000 times bootstrapping (Swofford 2002). The TCS network and related sequence statistics were obtained by using POPART program (http://popart.otago.ac.nz).

Table 1. List of three specimens of Olea europaea subsp. cuspidata L. along with the information regarding altitude, latitude, longitude and herbarium number

\begin{tabular}{|c|c|c|c|c|}
\hline Localities & Altitude & Latitude & Longitude & Voucher no. \\
\hline Chaharmahal and Bakhtiari Province, Dehedz - Lordgan, Iran & 1713 & $31^{\circ} 31^{\prime} 18^{\prime \prime}$ & $50^{\circ} 28^{\prime} 26^{\prime \prime}$ & HSBU2018700 \\
\hline Kohgiluyeh and Boyer-Ahmad Province, Khersaan Road, Iran & 1380 & $31^{\circ} 26 ' 59^{\prime \prime}$ & $50^{\circ} 28 ' 57 "$ & HSBU2018705 \\
\hline Chaharmahal and Bakhtiari Province, Lordgan, Monj, Gachahan, Iran & 1151 & $31^{\circ} 268^{\prime \prime}$ & $50^{\circ} 32^{\prime} 19^{\prime \prime}$ & HSBU2018711 \\
\hline Chaharmahal and Bakhtiari Province, Lordgan, Monj, Gachahan, Iran & 1592 & $35^{\circ} 55^{\prime} 41^{\prime \prime}$ & $57^{\circ} 41^{\prime} 53^{\prime \prime}$ & HSBU2018712 \\
\hline
\end{tabular}


Table 2. The comparison between six wild specimens and four cultivated specimens applied for ITS

\begin{tabular}{lc}
\hline \multicolumn{1}{c}{ Species } & Accession number \\
\hline Olea europaea & KY313879.1 \\
Olea europaea & AF231866.1 \\
Olea europaea & KY313880.1 \\
Olea europaea subsp. cuspidata & HQ117893 \\
Olea paniculata & AF231867.1 \\
Olea europaea subsp. cuspidata & AY040810.1 \\
Olea europaea subsp. cuspidata & AM933049.1 \\
Olea europaea subsp. cuspidata & AM933048.1 \\
Olea europaea subsp. cuspidata & AM933047.1 \\
Olea europaea subsp. cuspidata & AM933046.1 \\
\hline
\end{tabular}

Table 3. The comparison between six wild specimens and five cultivated specimens applied for trnl-F

\begin{tabular}{|c|c|}
\hline Species & Accession number \\
\hline Olea europaea subsp. cuspidata & AY040810.1 \\
\hline Olea europaea subsp. cuspidata & AM933043.1 \\
\hline Olea europaea subsp. cuspidata & AM933045.1 \\
\hline Olea europaea subsp. cuspidata & AM933047.1 \\
\hline Olea europaea subsp. cuspidata & AM933048.1 \\
\hline Olea europaea subsp. cuspidata & AM933049.1 \\
\hline Olea europaea & AY040811.1 \\
\hline Olea europaea & FJ490798.1 \\
\hline Olea europaea & KY313879.1 \\
\hline Olea europaea & HQ117895.1 \\
\hline Olea europaea & AF231866.1 \\
\hline
\end{tabular}

Table 4. Two out-groups applied for rpl16 sequencing

\begin{tabular}{lc}
\hline \multicolumn{1}{c}{ Species } & Accession number \\
\hline Olea europeaea cultivar Frantolo & GU931818.1 \\
Olea europeaea cultivar Bianchera & NC 013707.2 \\
\hline
\end{tabular}

\section{RESULTS AND DISCUSSION}

ITS sequences obtained after curation produced $377 \mathrm{bp}$ long sequences, which could differentiate wild and cultivated olives from each other. The preliminary statistics of the ITS sequences produced the nucleotide diversity $(\mathrm{Pi})=0.26$, the number of nucleotide differences between wild and cultivated olive samples was 174, and Tajima's D test $(D)=2.82$. Short sequences were identified which were specific for either plant species which can be used as DNA barcodes (Figure 1).

Maximum likelihood (ML) phylogenetic tree based on ITS sequences (Figure 2) separated the studied plant samples of the two species in separate clades with $100 \%$ bootstrap value.

\section{CP-DNA trnL-F region}

$T r n L-F$ region sequences obtained in the wild and cultivated olive samples after curation produced 73 bp long sequences. The two olive species studied differed in 35 nucleotides, with nucleotide diversity $(\mathrm{Pi})=0.27$, and Tajima's D statistic: $\mathrm{D}=1.48(\mathrm{p}=0.16)$. Some of the short sequences of TrnL-F chloroplast inter-genie region also could differentiate the two plant species from each other and can act as barcodes (Figure3). Maximum likelihood (ML) phylogenetic tree based on trnL-F sequences (Figure 4). separated the studied plant samples of the two species in separate clades with $100 \%$ bootstrap value.

\section{Chloroplast rpL16 sequences}

Chloroplast rpl16 region sequences after curation produced a total length of 583 bp DNA segment with 229 polymorphic sites, $\mathrm{Pi}=0.067$. The two olive species differed in 218 nucleotides, few of which were unique in either species and can be used in olive species barcoding (Figure 5). The ML phylogenetic tree was obtained with dual purposes. First to differentiate the wild olive (denoted in Figure 6) from the cultivated samples studied (Samples A1), and second, to check the local medicinal plant products (Samples A2-A6, in Figure 6).

The result showed that wild olive is separated from the cultivated olive samples and is placed in a distant clade. Therefore, based on rpL16 sequences these two olive species can be differentiated. Out of 5 plants from the medicinal shops investigated, four samples were placed closer to the wild olive plant and only 2 samples (A2 and A6) were placed close to the cultivated olive plant. Therefore, it seems that misidentification of these two different plant species by the local shops can cause potential abortion problems for the consumers (Kadam and Gaykar 2018). As stated before, usually, the consumers purchase the cultivated olive leaves for controlling the blood pressure, but instead the leaves of wild olives have been sold to them which is used for abortion.

The result of the present study indicates that using a combination of molecular barcodes present in ITS, $\operatorname{trnL}-F$ and rpL16 sequences can help to differentiate the two olive species $O$. europeae, and $O$. cuspidata, and can improve the correct marketing of these medicinal plant taxa. 


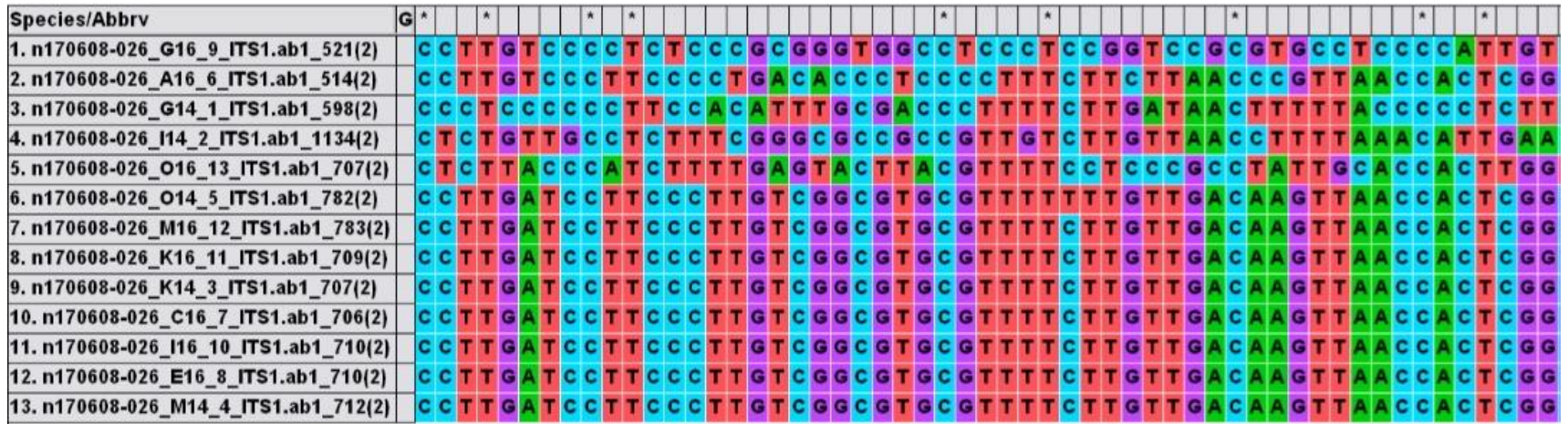

Figure 1. Representative barcoding nucleotides in ITS region of wild and cultivated olive studied

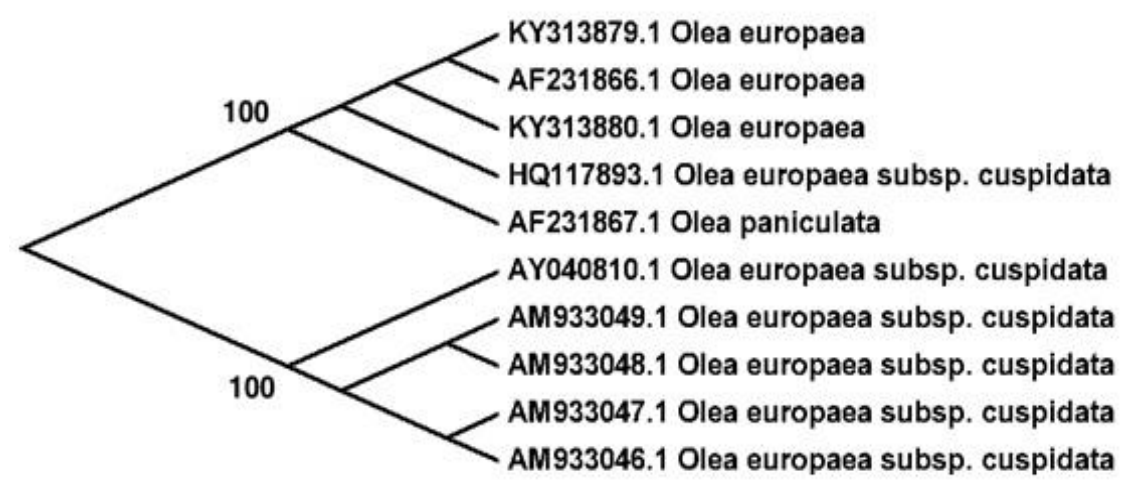

Figure 2. ML phylogenetic tree of wild and cultivated olives based on ITS sequences showing the species differentiation. (Numbers on the branches are bootstrap value).

\begin{tabular}{|c|c|c|c|c|c|c|c|c|c|c|c|c|c|c|c|c|c|c|c|c|c|c|c|c|c|c|c|c|c|c|c|c|c|c|c|c|c|c|c|c|}
\hline Species/Abbrv & $\mathbf{G}^{\prime}:{ }^{*}|*|$ & & a & * & & & ${ }^{*}$ & & * & & ${ }^{\prime}$ & & & ${ }^{*}$ & * & & & & & $*$ & * & 1 & & & ${ }^{*}$ & & & ${ }^{*}{ }^{\circ}$ & & $1 .{ }^{*}$ & & ${ }^{*}$ & & & & $\star$ & & & & 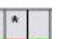 \\
\hline 1. $w(2)$ & GA & $G T$ & $T G$ & A C & $C T$ & & c & $T / C$ & $c$ & A 7 & |A & G & TA & & GA & & $C T$ & TA & & $\mathbf{T A}$ & $A C$ & & A & A C & & $C A$ & & c & & $T T$ & & G $T$ & & & $\mathbf{T} \mid \mathbf{A}$ & & $C T$ & G G & & $T / A$ \\
\hline 2. $A 1(2)$ & $G A$ & & $T G$ & $A 7$ & & & c & & c & A 7 & A & $\mathrm{G}^{7}$ & $\mathbf{T} \mathbf{A}$ & $\mathbf{T}$ & $G A$ & $A$ & & $\mathbf{A}$ & & $\mathbf{T} \mathbf{A}$ & $A C$ & & A & A C & $\mathrm{T}$ & $C A$ & & c & & $\mathbf{T} \mathbf{T}$ & & G & & $\mathbf{T T}$ & $\mathbf{T}|\mathbf{A}|$ & $T C$ & C T & $G G$ & A & $\mathrm{T}$ A \\
\hline 3. $A 3(2)$ & GA & & C G & A & $C A$ & & c & c c & c & & A & & $\mathbf{T} A$ & $\mathbf{T}$ & G A & $A$ & C T & I A & & $\mathbf{T} \mathbf{A}$ & $A C$ & & & $A C$ & $=T$ & C A & & c & & $T T$ & & G & & & $\mathbf{T} \mathbf{A}$ & & c T & G G & & $\mathrm{T} \mid \mathrm{A}$ \\
\hline 4. $A 4(2)$ & GA & & $C G$ & $A$ & $c T$ & & c & & c & A 7 & $\Gamma$ & G & TA & $T$ & GA & $A$ & $G G$ & $3 \mathrm{~A}$ & A 1 & TA & AC & c c & & $A C$ & $=T$ & $C A$ & & c & & $T T$ & & G & & & $\mathbf{T A}$ & & $\mathbf{G A}$ & GG & & TA \\
\hline 5. $A 5(2)$ & GA & & $C G$ & A & $c T$ & & c & & c & A 1 & $\Gamma$ A & & TA $\mathbf{A}$ & $\mathbf{T}$ & GA & $G$ & & $3 \mathrm{~A}$ & G 1 & $\mathbf{T} \mathbf{A}$ & $A C$ & $c \mathrm{c}$ & & $A C$ & $=T$ & C A & & c & & $T T$ & & G & & & $\mathbf{T} \mathbf{A}$ & & c T & G G & & T A \\
\hline 6. $A 2(2)$ & $G A$ & & C G & A & $c c$ & $G$ & c & & $c$ & & C A & $\mathbf{T}$ & GG & $T$ & $G G$ & 3 A & & $\mathrm{rc}$ & & & & $\mathrm{T} C$ & & & $=T$ & A T T & & c & & $T T$ & & GC & & $A C$ & C A & & c c & G G & & $T T$ \\
\hline 7. $A 6(2)$ & GA & & cG & A & ce & 36 & c & & c & GC & CA & $\mathbf{T}$ & GG & $\mathbf{T}$ & $G G$ & A & & r c & $A$ & C A & A 1 & $\mathrm{~T} C$ & c & AC & $\mathrm{T}$ & A $T$ & & c & & $T 7$ & & $\mathbf{G}$ & & $A C$ & C A & & c c & Go & 3) A & $\mathbf{T} \mathbf{T}$ \\
\hline 8. GU931818.1_Olea_europaea_ & GA & & CG & A & $c c$ & & c & C G & $c$ & $G C$ & & $T$ & GG & $\mathrm{T}$ & G G & A A & & & A & & A 1 & & & AC & & A T & & & $A C$ & $T$ & & G & & $A C$ & CA A & $T C$ & c c & G C & & $\mathbf{T} T$ \\
\hline 9. NC_013707.2_Olea_europaea & GA & & c & A & $\mathrm{cc}$ & & & & c & & & & & & & & & & & & & & & & & & & & & & & & & & C A & & & & & $T T$ \\
\hline
\end{tabular}

Figure 3. Representative chloroplast trnL-F sequences in wild and cultivated olives studied

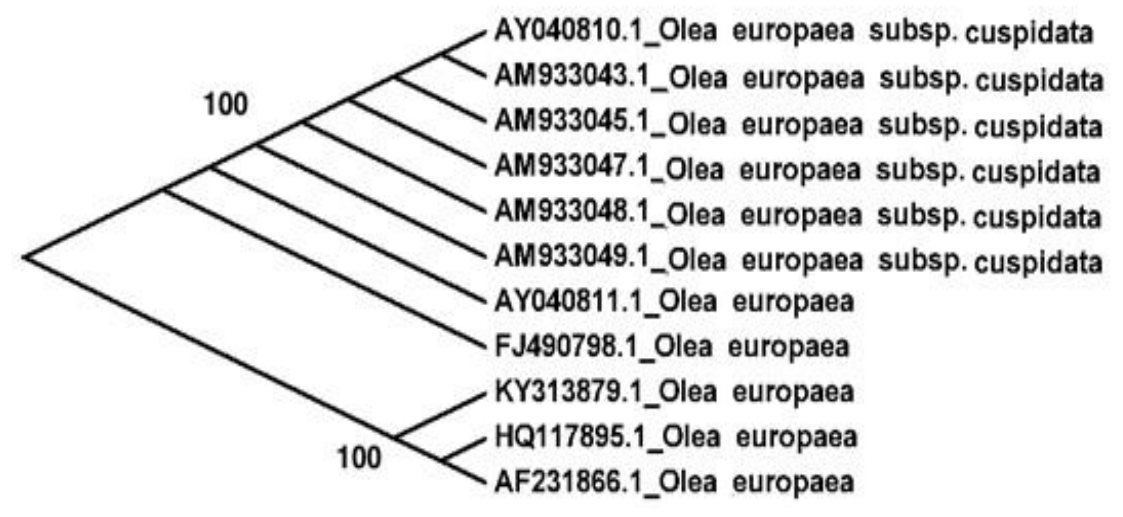

Figure 4. ML phylogenetic tree of wild and cultivated olives based on $\operatorname{trn} L-F$ sequences. (Numbers on the branches are bootstrap value) 


\begin{tabular}{|c|c|c|c|c|c|c|c|c|c|c|c|c|c|c|c|c|c|c|c|c|c|c|c|c|c|c|c|c|c|c|c|c|c|c|c|c|c|c|}
\hline Species/Abbrv & G: & & * & & & 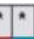 & & $1 *$ & & * & $*$ & & & & $*$ & * & & * & ${ }^{*}$ & & & & & & & & & 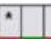 & & & & 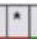 & * & & $*$ & & * & \\
\hline 1. HQ117893.1_subsp._cuspidata & $T C T$ & $T T$ & $\mathbf{T T}$ & & & C & & & & & & $C \mathbf{T}$ & & TA & & & & & & & & & & $A T$ & & & & $\mathbf{T}$ & & & & & & & & & & cT \\
\hline 2. FJ490798.1_Olea_europaea & TCC & & & & & $r c$ & & r c & & & & & & & & $\mathbf{T} T$ & & & & TA & & & & & & & & & & & & & & & & & & $T T$ \\
\hline 3. KY313879.1_Olea_europaea & T C T & $\mathbf{T} \mathbf{T} T$ & $\mathbf{T C}$ & c & A & $\mathrm{T}$ & & $\mathrm{r}$ & A & $|A|$ & $\mathbf{T}$ & C $\mathbf{T}$ & c & & $\mathbf{T}$ & C $\mathbf{T}$ & & $T A$ & & $T T$ & & & G $|A|$ & $\mathbf{A} \mathbf{T}$ & & $G A$ & & $\mathbf{T} \mid \mathbf{A}$ & & & & $\mathbf{T}$ & A T T & $C \mathrm{C} A$ & A $T$ & & & c T \\
\hline 4. HQ117895.1_Olea_europaea & $\mathrm{TCT}$ & & $\mathrm{TC}$ & c & & rc & & TC & & A & $\mathbf{T}$ & C T & c & & $\mathbf{T}$ & C T & & T A & & $\mathbf{T} T$ & & & & & & G A & & & & & & $T$ & A T & & A $\mathbf{T}$ & & & c T \\
\hline 5. AF231866.1_Olea_europaea & $T$ C T & $\mathbf{T} \mathbf{T} T$ & $\mathbf{T C}$ & c & A 7 & $r c$ & & $T C$ & & A & $\mathbf{T}$ & C T & c & TA & $\mathbf{T}$ & C T & & $\mathbf{T A}$ & & $\mathbf{T} \mathbf{T}$ & & & $G|A|$ & A T & & GA & & $\mathbf{T A}$ & $T \mathbf{T}$ & & & $\mathbf{T}$ & A $\mathbf{T}$ & & A $T$ & $T$ & C/A & c T \\
\hline 6. AY040811.1_Olea_europaea & T T T & & & $\mathbf{T}$ & & rc & & $\mathbf{T} \mathbf{C}$ & & A & $\mathbf{T}$ & $\mathbf{T} \mathbf{T}$ & $T$ & & $\mathbf{T}$ & $\mathbf{T} \mathbf{T}$ & & $C A$ & & $\mathbf{T} \mathbf{T}$ & $A$ & & & $T T$ & & $A A$ & & $\mathbf{T} \mathbf{T}$ & c T & & & $T$ & & & C T & & & $\mathbf{T} \mathrm{T}$ \\
\hline 7. AM933049.1_subsp._cuspidata & $\mathbf{T} \mathbf{T}$ & $\mathbf{T} C 1$ & $\mathbf{T} \mathbf{T}$ & $\mathbf{T}$ & A & $\mathrm{c}$ & & $\mathbf{T} \mathrm{c}$ & & A & $\mathbf{T}$ & $\mathbf{T} \mathbf{T}$ & $T$ & & $\mathbf{T}$ & $\mathbf{T} \mathbf{T}$ & & C A & & $\mathbf{T} \mathbf{T}$ & $A C$ & $c$ & A $\mathbf{T}$ & $T T$ & & AA & & & C T & & & $\mathrm{T}$ & C T & & C T & & & $\mathbf{T} T$ \\
\hline 8. AM933048.1-subsp._cuspidata & T T T & & $\mathbf{T} \mathbf{T}$ & $T$ & & $r c$ & & $\mathrm{TC}$ & & & & & & & $\mathbf{T}$ & $\mathbf{T} \mathbf{T}$ & & $C A$ & & & & & A T & $\mathbf{T} T$ & & $A A$ & & $\mathbf{T} \mathbf{T}$ & & & & $\mathbf{T}$ & & & C T & & $\mathbf{T}$ & $\mathbf{T} T$ \\
\hline 9. AM933047.1_subsp._cuspidata & $\mathbf{T} T \mathbf{T}$ & $\mathbf{T} \mathrm{C}$ & $T T$ & $\mathbf{T}$ & & rc & & $\mathbf{T} C$ & & & & $\mathbf{T} T$ & & & $\mathbf{T}$ & $T T$ & & C A & & $\mathbf{T} T$ & $A C$ & & A T & $T T$ & & $A A$ & & $\mathbf{T} \mathbf{T}$ & C T & & & $T$ & C T & & $C \mathbf{T}$ & & & $T \mathrm{~T}$ \\
\hline 10. AM933045.1_subsp._cuspidat: & $T T T$ & & & $\mathbf{T}$ & A & & & T C & & A & $\mathbf{T}$ & $\mathbf{T} T$ & $T$ & & $\mathbf{T}$ & $T T$ & & $C A$ & & $T T$ & A & & A T T & T 1 & & $A A$ & & $\mathbf{T T}$ & C T & & & $\mathbf{T}$ & & $\mathrm{T}$ & $C T$ & & $\mathbf{T}$ & $\mathbf{T} \mathrm{T}$ \\
\hline 11. AY040810.1_subsp._cuspidate & T T T & $\mathbf{T} C 1$ & $\mathbf{T} T$ & $\mathbf{T}$ & A & rc & & & & & $\mathbf{T}$ & $\mathbf{T} \mathbf{T}$ & & & $\mathbf{T}$ & $\mathbf{T} T$ & & C A & & $\mathbf{T} \mathbf{T}$ & A & c & A T & $\mathbf{T} 1$ & & A A & & $\mathrm{TT}$ & C T & & & $\mathbf{T}$ & C T & $\mathrm{T}$ & C T & c & $\mathrm{T}$ A & $T T$ \\
\hline 2. AM933043.1_subsp._cuspidat: & $\mathrm{T} T \mathrm{~T} T$ & $T$ & $\mathbf{T} T$ & & & & & & & & & & & & & $T$ & & & & & & & & & & & & & & & & & & & & & & \\
\hline
\end{tabular}

Figure 5. Representative rpL16 sequences in wild and cultivated olive plants

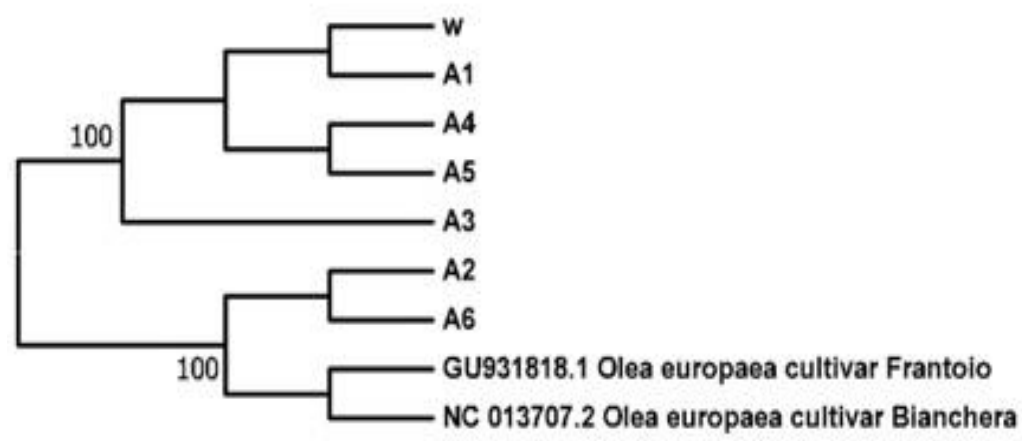

Figure 6. ML phylogenetic tree of the wild and cultivated as well as market sold olive samples based on rpL16 sequences. $(\mathrm{w}=$ wild olive, A1-A6 = Market sold samples). (Numbers on branches are bootstrap value)

\section{Discussion}

The medicinal plant products and the consumers health can be improved by scientific and regular monitoring of the local markets. Nowadays advanced approaches can be utilized for market product control. DNA barcoding is one of the recent molecular approaches for such product marketing improvement which in turn improves the consumers' health (Sheidai et al. 2019).

DNA barcoding allows the correct identification of the biological species. Although these barcodes are comprised of short sequences and represent only a small fraction of the total DNA, they can provide adequate nucleotide variability as well as species/ varietal sequence peculiarity which can differentiate most of the species from each other (Barcaccia et al. 2016; Sheidai et al. 2019). Therefore, in recent days, DNA barcoding approach has been practiced in the food industry and medicinal plant products marketing to avoid food piracy and adulteration of the products (Barcaccia et al. 2016).

Recent investigations concerned with the olive tree are mainly focused on screening adulteration in olive oil by using different methodologies, including DNA barcodes (see, for example, Kumar et al. 2011; Barcaccia et al. 2016). Due to nutritional value of the olive (Olea europaea), it has a high demand and therefore, is subjected to adulteration and fraud. This is usually done through the mixing of lower-cost plant oils like soya, canola, maize, sunflower, and sesame, with olive oil (Barcaccia et al. 2016).
The use of a combination of barcodes obtained from psbA-trnH and partial coding region of matK of the plastid genome was able to identify the presence of canola and sunflower in olive oil samples (Kumar et al. 2011).

The present investigation was concerned with olive leaf product misidentification/adulteration in Iran local medicinal plant market as these plant products have different properties. The cultivated olive is utilized for blood pressure control, but the leaves of wild olive in the form of tea have been used for abortion. We showed that a combination of nuclear ITS region along with short sequences in $\operatorname{trnL}-F$ and rpL16 chloroplast can differentiate the two olive species and uncover adulteration in the local markets.

Besnard et al. (2001) utilized molecular markers to study the cp-DNA variation in cultivated and wild Mediterranean olive trees. The discriminating power of $\mathrm{cp}-$ DNA variation was particularly low for the cultivated olive tree with one predominating haplotype, but more diversity was detected in wild populations.

Besnard et al. (2011) and Pérez-Jiménez et al. (2013) suggested that cp-DNA markers will have applications for a comparative study of the dynamic of wild olive tree populations in different environments, such as archipelagos and Saharan mountains. These data altogether suggest that we can use barcode sequences of both nuclear and plastid genomes to avoid olive plants' misidentification for the medicinal plant market. 
In conclusion, the present study emphasizes the use of modern molecular barcoding to improve olive leaf marketing in medicinal local shops. This approach can avoid misidentification of the closely related species of olive which have different medicinal properties. This, in turn, avoid harm to human health.

\section{ACKNOWLEDGEMENTS}

This research is supported by the Islamic Azad University, Science and Research Branch, Tehran, Iran. The authors wish to thank the assistance of Fahimeh Koohdar in the laboratory of Shahid Beheshti University for providing the equipment for the present investigation.

\section{REFERENCES}

Abaza L, Taamalli HN, Zarrouk M. 2015. Olive tree (Olea europeae L.) leaves: Importance and advances in the analysis of phenolic compounds. Antioxidants 4 (4): 682-698. DOI: 10.3390/antiox4040682.

Altinyay C, Güvenç A, Altun ML. 2011. Antioxidant activities of oleuropein and the aqueous extracts of Olea europaea L. varieties growing in Turkey. Turk J Pharm Sci 8 (1): 23-30.

Barcaccia G, Lucchin M, Cassandro M. 2016. DNA barcoding as a molecular tool to track down mislabeling and food piracy. Diversity 8 (2): 1-16. DOI: 10.3390/d8010002

Besnard G, Baradat P, Berville A. 2001. Genetic relationships in the olive (Olea europaea L.) reflect multilocal selection of cultivars. Theor Appl Genet 102 (2): 251-258. DOI: 10.1007/s001220051642

Besnard G, Hernández P, Khadari, B, Dorado G, Savolainen V. 2011. Genomic profiling of plastid DNA variation in the Mediterranean olive tree. BMC Plant Biol 11 (1): 1-12. DOI: 10.1186/1471-2229-11 80

El Beyrouthy M, Abi-RizkA. 2013. DNA fingerprinting: the new trend in fighting the adulteration of commercialized and cultivated medicinal plants. Adv Crop Sci Technol 1 (4): 1000e107. DOI: 10.4172/23298863.1000e107

Ghorbani A, Saeedi Y, de Boer HJ. 2017. Unidentifiable by morphology: DNA barcoding of plant material in local markets in Iran. PLoS One 12, e0175722. DOI: 10.1371/journal.pone.0175722

Green PS. 2002. A revision of Olea L. (Oleaceae). Kew Bull 57 (1): 91 140. DOI: $10.2307 / 4110824$

Heubl G. 2010. New aspects of DNA-based authentication of Chinese medicinal plants by molecular biological techniques. Planta Med 76 (27): 1963-1974. DOI: 10. 1055/s-0030-1250519

Hashmi MA, Khan A, Hanif M, Farooq U. 2015. Traditional uses, phytochemistry, and pharmacology of Olea europaea (olive). EvidBased Compl Alt. DOI: 10.1155/2015/541591

Kadam A, Gaykar B. 2018. Phytochemical Analysis of Contraceptive Plants. LAP LAMBERT Academic Publishing, Mauritius.
Kirzam M, Jakse J, Baricevic D, Javornik B, Prosek M. 2006 Robust CTAB-activated charcoal protocol for plant DNA extraction. Acta Agric Slov 87(2): 427-433

Kumar S, Kahlon T, Chaudhary S. 2011. A rapid screening for adulterants in olive oil using DNA barcodes. Food Chem 127 (3): 1335-1341. DOI: 10.1016/j.foodchem.2011.01.094

Lockyer S, Rowland I, Spencer JPE, Yaqoob P, Stonehouse W. 2017. Impact of phenolic-rich olive leaf extract on blood pressure, plasma lipids and inflammatory markers: a randomized controlled trial. Eur J Nutr 56 (4): 1421-1423. DOI: 10.1007/s00394-016-1188-y

Masoko P, Makgapeetja DM. 2015. Antibacterial, antifungal and antioxidant activity of Olea africana against pathogenic yeast and nosocomial pathogens. BMC Compl Altern Med 15 (1): 1-9. DOI: 10.1186/s12906-015-0941-8

Pasqualone A, Montemurro C, di Rienzo V, Summo C, Paradiso VM, Caponio F. 2016. Evolution and perspectives of cultivar identification and traceability from tree to oil and table olives by means of DNA markers. J Sci Food Agric 96 (11): 3642-3657. DOI: $10.1002 /$ jsfa.7711

Pérez-Jiménez M, Besnard G, Dorado G, Hernandez P. 2013. Varietal tracing of virgin olive oils based on plastid DNA variation profiling. PLoS One 8 (8), e70507. DOI: 10.1371/journal.pone.0070507

Shaw J, Small RL. 2005. Chloroplast DNA phylogeny and phylogeography of the North American plums (Prunus subgenus Prunus section Prunocerasus, Rosaceae). Am J Bot 92 (12): 2011 2030. DOI: 10.3732/ajb.92.12.2011

Sheidai M, Zanganeh S, Haji-Ramezanali R, Nouroozi M, Noormohammadi Z, Ghsemzadeh-Baraki S. 2013. Genetic diversity and population structure in four Cirsium (Asteraceae) species. Biologia 68 (3): 384-397. DOI: 10.2478/s11756-013-0162-x

Sheidai M, Tabaripour R, Talebib SM, Noormohammadi Z, Koohdar F. 2019. Adulteration in medicinally important plant species of Ziziphora in Iran market: DNA barcoding approach. Ind Crop Prod 130: 627-633. DOI: 10.1016/j.indcrop.2019.01.025

Somova LI, Shode FO, Ramnanan P, Nadar A. 2003. Antihypertensive, antiatherosclerotic and antioxidant activity of triterpenoids isolated from Olea europaea, subspecies africana leaves. 84 (2-3): 299-305 DOI: 10.1016/S0378-8741(02)00332-X

Srirama R, Santhosh Kumar JU, Seethapathy GS, Newmaster SG, Ragupathy SR, Ganeshaiah KN, Shaanker RU, Ravikanth G. 2017. Species adulteration in the herbal trade: causes, consequences and mitigation. Drug Saf 40 (8): 651-661. DOI: 10.1007/s40264-0170527-0

Swofford DL. 2002. PAUP*. Phylogenetic analysis using parsimony and other methods), Version 4. Sinauer Associates, Sunderland, MA, USA.

Tamura K, Peterson D, Peterson N, Stecher G, Nei M, Kumar S. 2012. MEGA5: molecular evolutionary genetics analysis using maximum likelihood, evolutionary distance, and maximum parsimony methods. Mol Biol Evol 28 (10): 2731-2739. DOI: 10.1093/molbev/msr121

Yu N, Wei YL, ZhuY, Zhu N, Wang YL, Zhang HP, Sun AD. 2018. Integrated approach for identifying and evaluating the quality of Marsdenia tenacissima in the medicine market. PLoS One 13, e0195240. DOI: 10.1371/journal.pone0195240

Zohary D. 1995. Olive, Olea europaea (Oleaceae). In: Smartt J, Simmonds NW (eds) Evolution of Crop Plants. Longman Scientific \& Technical, Harlow, England. 